\title{
Liquidity Commonality in an Emerging Market: Evidence from the Amman Stock Exchange
}

\author{
Mohammad Tayeh $^{1}$, Adel Bino ${ }^{1}$, Diana Abu Ghunmi ${ }^{1} \&$ Ghada Tayem ${ }^{1}$ \\ ${ }^{1}$ Department of Finance, School of Business, The University of Jordan, Amman, Jordan \\ Correspondence: Mohammad Tayeh, Finance Department, School of Business, The University of Jordan, \\ Amman 11942, Jordan. Tel: 962-6-535-5000 ext. 24271. E-mail: m.tayeh@ju.edu.jo
}

Received: December 2, 2014

Accepted: December 15, 2014

Online Published: January 25, 2015

doi:10.5539/ijef.v7n2p203

URL: http://dx.doi.org/10.5539/ijef.v7n2p203

\begin{abstract}
The financial crises, such as the market crash of October 1987, the 1997 East Asian financial crisis and the 1998 long-term capital management (LTCM) crisis, have all shed fresh light on the importance of systematic liquidity (i.e., market-wide liquidity factor). Following the new trend in market microstructure research, this study examines the commonality in liquidity for the Amman Stock Exchange (ASE), one of the emerging markets in the MENA region. Based on data for 247 firms from March 26, 2000 to December 31, 2011, and applying the market model of Chordia et al. (2000), the results provide strong evidence of the presence of market-wide commonality in liquidity. The cross-sectional mean of the estimated coefficient of concurrent market liquidity is statistically significant for all liquidity measures, apart from the price impact measure. Price impact aside, the results show that commonality is pervasive across all size-based portfolios. The results also show an insignificant industry component in individual stocks' liquidity.
\end{abstract}

Keywords: Liquidity, commonality, order-driven market, ASE, market-wide liquidity

\section{Introduction}

The beginning of this century witnessed a huge shift in the attention of market microstructure literature towards investigating the common components of liquidity, which is known as commonality in liquidity. The emergence of this new line of research goes back to the seminal work of Chordia et al. (2000) who were the first to examine commonality in liquidity in the NYSE. Similar evidence is also found by Huberman and Halka (2001) and Hasbrouck and Seppi (2001). Brockman and Chung (2002) and Fabre and Frino (2004) extend this line of research to different market settings. They examine the co-movement in liquidity in pure order-driven markets, particularly the Hong Kong and the Australian Stock Exchanges. However, their evidence on commonality in such markets is mixed.

Notwithstanding the importance of these studies, the evidence provided on commonality comes from developed markets. Studies that examine the commonality in liquidity in emerging markets are very few. One notable exception includes Pukthuanthong-Le and Visaltanachoti (2009) who provide evidence on commonality from the Stock Exchange of Thailand. However, their results cannot be generalized to other emerging markets because the structure of the Thai stock market is significantly different in terms of the rules of trading mechanisms, degree of transparency, and tick size (Comerton-Forde \& Rydge, 2006). Therefore, this study aims to provide further evidence on commonality in liquidity from another emerging market, namely the Jordanian Stock Market, that represents other markets in the countries of the Middle East and North Africa (henceforth MEAN). Among MEAN markets, the Jordanian Stock Market has the largest market capitalization as it equals $116.80 \%, 94.25 \%$, 87.05\% of GDP for 2010, 2011, and 2012 respectively (Note 1).

Investigating commonality in liquidity in emerging markets from the MENA region is important for several reasons. First, evidence concerning the existence of a common component cross stocks' liquidity from the MENA region is non-existent. Second, stock markets in the MEAN region are less developed than the emerging markets in the Asian region and suffer from some institutional underdevelopments: there are no market makers that are obligated to provide liquidity in the market through resolving the imbalance in order flow, and the lack of stringent information disclosure requirements that also drive illiquid markets within the MENA region (See Lagoarde-Segot and Lucey 2008 among others). 
Providing evidence regarding the presence of a common component cross stocks' liquidity in the Jordanian market, i.e. Amman Stock Exchange (ASE), is important for many markets' participants. Because market-wide liquidity is a non-diversifiable priced risk factor, investors holding stocks that are highly sensitive to market-wide shocks should ask for an additional premium to bear this risk (Amihud, 2002; Pastor \& Stambaugh, 2003; Acharya \& Pedersen, 2005; Martínez et al., 2005). Furthermore, since all markets in MENA countries have adopted the same execution system, i.e. an order-driven system, empirical evidence regarding this issue on the ASE will help regulators and exchanges to decide whether further regulations are required to improve market design.

This study contributes to the existing literature in several ways. First, it extends the empirical research on commonality to another equity market from new territory, namely the MENA region, where the existence of a market-wide component of liquidity has not yet been examined. Second, this study provides, for the first time, evidence for the existence of a common component in liquidity for the ASE, which can be viewed as an out-of-sample piece of evidence to test whether this phenomena only pertains to US, European and Asian markets. Third, the evidence provided regarding commonality from order-driven systems is inconclusive. Therefore, examining the commonality in order-driven market structures will provide new evidence that could resolve the current controversy in the literature.

Consistent with the previous literature on commonality, we find strong evidence of market-wide commonality in liquidity. The results show that all liquidity measures, apart from price impact, are significantly influenced by market-wide components. We also find evidence for the existence of the size effect in market-wide commonality in liquidity. Consistent with Brockman and Chung (2002) but in contrast to Chordia et al. (2000) the results show that the individual stock liquidity measured by quoted spread, proportional quoted spread and effective spread is the most sensitive to changes in market-wide liquidity for small size groups. However, the results do not support the existence of industry-wide commonality in liquidity which is consistent with Fabre and Frino (2004) and Galariotis and Giouvris (2007).

Section 2 of this paper describes the structure of the ASE and explains the rationale for commonality in order-driven markets. Section 3 presents the data and liquidity measures used in this paper. We discuss the empirical results in section 4; section 5 concludes with summary of the results.

\section{The Structure of the Jordanian Equity Market and Commonality in Liquidity}

Open market trading of financial securities in Jordan dates back to the 1930s, at which time buy and sell orders were executed through brokerage firms in an unregulated market. On January 1st 1978, the Amman Financial Market (AFM) was established as an organized market. Its main responsibilities include: enacting relevant legal requirements, organizing trading, and acting as custodian of traded financial securities. In 1999 comprehensive capital market reforms were undertaken to separate the supervisory and legislative roles from the executive role of the capital market. As a result, the Amman Stock Exchange (ASE) was established as an administrative institution managed by the private sector (i.e. the brokerage firms). The ASE is a non-profit institution that acts as an official market for trading securities in Jordan, and is supervised by the Jordan Securities Commission (JSC) (Note 2). Trading of stocks on the ASE takes place on two markets: the first market and the second market. A stock's liquidity besides other listing requirements determines in which market the stock will be traded.

In March, 2000, the ASE introduced the electronic limit order book into its order-driven market structure (Note 3). The limit orders that are submitted into the electronic trading system (ETS) are displayed and executed according to the priority of price and entry time. Sell (buy) orders are arranged from the lowest ask (highest bid) to the highest ask (lowest bid). Therefore, the bid-ask spread is the difference between the lowest ask price and the highest bid price.

In contrast to quote-driven markets, order-driven markets have no designated market makers that are obligated to provide liquidity to the market. The supply of liquidity depends on the limit orders that are submitted in the trading system by non-obligated traders and investors. Each investor decides whether to place a limit order or a market order depending on the intensity of his or her desire to trade and on the configuration of orders posted in the market (Handa et al., 1998). Therefore, how changes in market-wide liquidity will affect this liquidity-provision mechanism is the focus of this study. According to Brockman and Chung (2002), commonality in liquidity is expected to be more prevasive in order-driven markets due to the absence of obligatory market makers to maintain the liquidity of a stock. This is known as the free-exist aspect of order-driven markets, which allows traders to withdraw their orders, during market-wide liquidity shocks. On the other hand, the low barriers to entry in order-driven markets (i.e. free-entry aspect of order-driven systems) will attract more liquidity suppliers to the market when the cost of providing liquidity is high (i.e. higher spread). 
This will easily resolve any order imbalance across liquidity suppliers and thus commonality in liquidity is expected to be less pervasive. Consequently, whether commonality in liquidity is more or less pervasive in the ASE, a pure order-driven market is an issue that could be resolved empirically.

\section{Data}

A daily data set is obtained from the ASE for the period from March 26, 2000 to December 31, 2011, which covers the electronic trading regime. The basic data set consists of all stocks traded in the first and the second market that are listed and subsequently delisted, to control for survival bias. Some stocks are infrequently traded and cannot provide reliable information (Chordia et al., 2000; Fabre \& Frino, 2004). Therefore, a trading frequency filter is applied. To be included, stock has to be actively traded for at least 20 trading days during a year (Note 4). After applying this criterion, the number of stocks that are included in the sample are 247 out of 261 during 2,890 trading days. The daily data includes closing prices, trading volume (i.e. number of shares traded), number of shares outstanding, best bid price and best ask price for each stock. Also, the data include the daily closing prices of the stock market index, from which market return variables are calculated.

\subsection{Liquidity Measures}

Direct liquidity measures for emerging markets using intra-day data are not available. However, the dataset of this study include sufficient information to calculate daily liquidity measures that are widely used in market microstructure literature. For each stock included in the sample, we use the following alternative variables to proxy liquidity:

First, Quoted and Proportional Bid-ask Spread: The bid-ask spread is one of the most common measures of liquidity. According to Demsetz (1968), bid-ask spread represents the cost of immediacy. That is, when traders want to quickly fill their orders they buy (sell) at the current ask (bid) price. The ask (bid) price represents the concession (premium) for the immediate sell (buy) transaction. For small investors, it is accurate and an effective measure of the liquidity of a stock. By calculating the proportional bid-ask spread, which is the bid-ask spread divided by the midpoint of the quote, liquidity may be compared across stocks with different prices (see e.g. Aitkena \& Comerton-Forde, 2003; Tayeh, 2010). The quoted and the proportional bid-ask spread is calculated as follows:

$$
\begin{array}{r}
Q B A_{i, t}=A s k_{i, t_{i}-B i d_{i, t}} \\
P Q B A_{i, t}=\frac{\left(A s k_{i, t}-B i d_{i, t}\right)}{\left(\left(A s k_{i, t}+B i d_{i, t}\right) / 2\right)}
\end{array}
$$

Where $\mathrm{QBA}_{\mathrm{i}, \mathrm{t}}$ and $\mathrm{PQBA} \mathrm{A}_{\mathrm{i}, \mathrm{t}}$ are, respectively, the quoted spread and proportional quoted spread for stock $i$ at day $t$ respectively, ask $\mathrm{i}_{\mathrm{i}, \mathrm{t}}$ and bid $_{\mathrm{i}, \mathrm{t}}$ are the ask price and bid price for stock $i$ at day $t$. The denominator of the equation (2) represents the midpoint of the quote.

Second, Effective Spread (i.e. Roll Measure): A measure of effective spread is developed by Roll (1984) which is based on the serial co-variance of the change in daily stock prices. Roll shows that the serial co-variance is calculated as follows:

$$
E S_{i, t}=2 \sqrt{-\operatorname{cov}\left(\Delta P_{i, t}, \Delta P_{i, t-1}\right)}
$$

Where $E S_{i, t}$ is the effective spread for stock $i$ at day $t, P_{t}$ and $P_{t-1}$ are the observed price on day $t$ and $t-1$ respectively.

Third, Modified Effective Spread: The previous equation of Roll measure will not be estimated when the sample serial co-variance is positive; therefore, Goyenko et al. (2009) use a modified version of Roll measure, which substitutes the positive serial co-variance with a default numerical value of zero. The modified version of Roll measure is estimated as follows:

$$
\operatorname{MES}_{i, t}=\left\{\begin{array}{cc}
2 \sqrt{-\operatorname{cov}\left(\Delta P_{i, t}, \Delta P_{i, t-1}\right)} & \text { when } \operatorname{cov}\left(\Delta P_{t}, \Delta P_{t-1}\right)<0 \\
0 & \text { when } \operatorname{cov}\left(\Delta P_{t}, \Delta P_{t-1}\right) \geq 0
\end{array}\right.
$$

Where $M E S_{i, t}$ is modified effective spread for stock $i$ at day $t$. 
Table 1. Summary statistics of liquidity variables

Panel A. Cross-sectional statistics for time series means

\begin{tabular}{lccccc}
\hline & Mean & Median & Std Dev & Minimum & Maximum \\
\hline PIMPACT & 0.065 & 0.021 & 0.128 & 0.000 & 1.149 \\
TOV & 0.004 & 0.002 & 0.007 & 0.000 & 0.047 \\
$\boldsymbol{E S}$ & 0.030 & 0.022 & 0.049 & 0.000 & 0.703 \\
$\boldsymbol{M E S}$ & 0.016 & 0.012 & 0.022 & 0.000 & 0.289 \\
$\boldsymbol{Q B A} \boldsymbol{P}$ & 0.321 & 0.133 & 0.598 & 0.012 & 5.925 \\
$\boldsymbol{P Q B A}$ & 0.227 & 0.131 & 0.264 & 0.004 & 1.925 \\
\hline
\end{tabular}

Panel B. Cross-sectional means of time series correlations between liquidity variable pairs for an individual stock

\begin{tabular}{lccccc}
\hline & PIMPACT & TOV & ES & MES & QBA \\
\hline $\boldsymbol{T O} \boldsymbol{V}$ & -0.160 & & & & \\
$\boldsymbol{E S}$ & -0.041 & 0.133 & & & \\
$\boldsymbol{M E S}$ & 0.004 & -0.046 & 1.000 & & \\
$\boldsymbol{Q B \boldsymbol { A }}$ & 0.075 & -0.022 & 0.089 & -0.004 & \\
$\boldsymbol{P Q B \boldsymbol { A }}$ & 0.083 & -0.026 & 0.040 & -0.022 & 0.910 \\
\hline
\end{tabular}

This table reports the summary statistics for liquidity variables over the entire sample period. Panel A reports the cross-sectional statistics computed from the time-series means of individual stock liquidity. Panel B reports the cross-sectional means of time series correlations between liquidity measure pairs for an individual stock. PIMPACT is Amihud's (2002) illiquidity ratio, which is defined as absolute return divided by currency trading volume. TOV is the turnover ratio, which is defined as trading volume divided by number of shares outstanding. $E S$ is Roll (1984) measure of the effective spread, which is defined as the serial co-variance of the change in the stock's price. MES is the modified version of Roll (1984) measure, which substitutes the positive serial co-variance with a default numerical value of zero. $Q B A$ is the quoted spread and $P Q B A$ is the proportional quoted spread, which is defined as the quoted spread divided by the quote midpoint. Each variable is calculated daily during the sample period from March 26, 2000 to December 31, 2011. During the sample period, the selected stock must have at least 235 active trading days.

Fourth, Amihud Illiquidity Ratio (Note 5): Amihud (2002) develops a rough measure of price impact known as illiquidity ratio. This measure captures the response of daily stock prices that is associated to one dollar of trading value. That is, it measures the impact of order flow on stock prices. Illiquidity ratio (i.e. price impact) is calculated as follows:

$$
\operatorname{PIMPACT}_{i, t}=\frac{\left|r_{i . t}\right|}{\text { Tvalue }_{i, t}}
$$

where PIMPACT $T_{i, t}$ is the price impact for stock $i$ at day $t, r_{i, t}$ is the stock return on day $t$ and Tvalue $_{i, t}$ is the stock currency volume (Jordanian dinar volume) on day $t$. This ratio is calculated over all positive-currency volume days, as the ratio is undefined for zero-volume days.

Fifth, Turnover Ratio: Turnover ratio is widely accepted measure of liquidity in market microstructure literature and it is relatively easy to measure using low frequency data (Datar et al., 1998). It is calculated as the number of shares traded divided by the number of shares outstanding:

$$
T O V_{i, t}=\frac{\text { Volume }_{i, t}}{\text { Number of shares outstanding }}
$$

Where $T O V_{i, t}$ is the turnover ratio for stock $i$ at day $t$, Volume $_{i, t}$ is the stock's number of shares traded in day $t$,

Table 1 shows the summary statistics of liquidity measures. Panel A represents the cross-sectional statistics of the time-series means of the level of liquidity variables. Consistent with Chordia et al. (2000), Fabre and Frino (2004) and Pukthuanthong-Le and Visaltanachoti (2009), the variables display right skewness; the median values are less than mean values. The quoted bid-ask spread is approximately JD 0.32 and the proportional quoted bid-ask spread is $22.7 \%$. Compared with previous studies, the quoted spread and the proportional spread reported on the ASE is higher than those reported in other markets. For example, for the New York Stock Exchange (NYSE), Chordia et al. (2000) report the quoted spread and the proportional spread as $\$ 0.32$ and $1.60 \%$. Fabre and Frino (2004) document the quoted spread and the proportional spread of \$A 0.03 and 3.91\% for the Australian Stock Exchange (ASX). Pukthuanthong-Le and Visaltanachoti (2009) show that the quoted spread and the proportional spread for the Stock Exchange of Thailand is THB 2.36 and 8.12\%. This shows that the liquidity in the ASE is 
very low compared with these markets. Panel B reports the correlation coefficients among liquidity variables. Little or no correlation appears to be between liquidity variables. Such correlations are not unusual: similar correlation degrees among liquidity variables have been documented in both developed and emerging markets (see e.g. Fabre \& Frino, 2004; Pukthuanthong-Le \& Visaltanachoti, 2009). This may imply that the choice of liquidity measure could possibly have a significant impact on the assessment of market liquidity (Aitken \& Comerton-Forde, 2003).

\section{Empirical Evidence}

\subsection{Evidence of Market Commonality}

The market model proposed by Chordia et al. (2000) is used to investigate the presence of market-wide commonality. This allows comparison of our results with those provided by other studies using the same model. For each stock, we estimate the following time-series regression model:

$$
\begin{aligned}
\Delta L i q_{i, t}= & \alpha_{i}+\beta_{i 1} \Delta L i q_{M, t}+\beta_{i 2} \Delta L i q_{M, t+1}+\beta_{i 3} \Delta L i q_{M, t-1}+\gamma_{i 1} \operatorname{Ret}_{M, t} \\
& +\gamma_{i 2} \operatorname{Ret}_{M, t+1}+\gamma_{i 3} \operatorname{Ret}_{M, t-1}+\gamma_{i} \sigma_{i, t}+\varepsilon_{i, t}
\end{aligned}
$$

Where $\Delta L i q_{i, t}$ is the daily percentage change in the liquidity variable for stock $i$ on day $t$ and $\Delta L i q_{M, t}$ is the concurrent percentage change in market-wide liquidity, which is calculated as equally weighted cross-sectional average of liquidity for all stocks traded in day $t$. In calculating market-wide liquidity, stock $i$ is excluded from the cross-sectional average to avoid a misleading constraint on the cross-sectional mean of coefficients (Chordia et al., 2000). $\Delta L i q_{M, t+1}$ and $\Delta L i q_{M, t-1}$ are one period lead and lag of the market average liquidity variable, which are included to control for any leaded and lagged adjustments (i.e. nonsynchronous liquidity changes) in commonality that result from thin trading. $\operatorname{Ret}_{M, t}, \operatorname{Ret}_{M, t+1}$ and $\operatorname{Ret}_{M, t-1}$ are concurrent, lead and lag market returns that are included to capture any spurious dependence that may result from the relationship between return and liquidity. Finally, $\sigma_{i, t}$, the squared stock return, is a proxy for stock volatility which is included as it may affect stock liquidity. Equation (7) is estimated by applying the GMM estimation method with Newey-West standard error correction to adjust for heteroscedasticity and auto-correlation.

To test the presence of commonality, the mean of beta coefficient related to concurrent percentage change in market liquidity, estimated from equation (7), should be significantly different from zero. More specifically, using the cross-sectional $t$-test, we test whether the cross-sectional average of $\beta_{i 1}$ equals to zero.

Table 2 reports the regression results of equation (7), where the daily percentage changes in a stock's liquidity regressed on the daily percentage changes in market-wide liquidity. The results provide ample evidence of commonality in liquidity. The cross-sectional average of the coefficient of concurrent market liquidity is significant for all liquidity measures with the exception of the price impact measure: a $t$-statistic of -0.69 . The $t$-statistics for other liquidity measures range from 2.76 to 8.24 .

Focusing on the size of the commonality effect on liquidity measures, the results indicate that turnover ratio shows the strongest commonality. The mean coefficient of the concurrent market liquidity in turnover ratio regression is 1.447 . Approximately $29 \%$ of these coefficients are significantly positive at $5 \%$ level.

Regression results based on effective spread and modified effective spread, also provide evidence supporting the existence of commonality, but it is less pervasive. The mean coefficient of the concurrent market liquidity for effective spread (modified effective spread) is $0.055(0.190)$, and about $62.23 \%(81.25 \%)$ of these coefficients are positive with roughly $15 \%$ (28\%) of these coefficients exceed the $5 \%$ one-tail critical value.

Considering the spread measures, quoted spread and proportional quoted spread, the average coefficient of the concurrent market liquidity is 0.372 and 0.910 , respectively. Approximately $67 \%$ (69\%) of the coefficients for quoted spread (proportional quoted spread) are positive and nearly 10\% (17\%) are significantly positive at the 5\% one-tailed critical level. Compared with the commonality results reported in other order-driven markets, our coefficients estimates for spread measures are larger than those reported by Brockman and Chung (2002) for the Hong Kong Stock Exchange and Fabre and Frino (2004) for the Australian Stock Exchange. This implies that commonality has a relatively stronger effect on spread measures for the ASE. However, commonality in the ASE is less (more) pervasive than commonality in quote-driven markets, namely the NYSE and the London Stock Exchange (LSE). The average coefficient of concurrent market liquidity for quoted spread (proportional quoted spread) in the ASE is smaller (larger) than those reported for the NYSE and the LSE by Chordia et al. (2000) and Galariotis and Giouvris (2007), respectively. The free-entry (free-exist) characteristic of order-driven markets compared with quote driven markets, implies that commonality might be less (more) pervasive in the former. However, the results of spread measures provide inconclusive evidence regarding the pervasiveness of 
commonality in an order-driven market (i.e. the ASE). Despite that, our results provide evidence that is consistent with previous studies and thus confirm that commonality in liquidity is a phenomenon that is not restricted to specific market structures and it is an important attribute in the ASE and could affect the process of liquidity provision.

Table 2. Market-wide commonality in liquidity

\begin{tabular}{|c|c|c|c|c|c|c|}
\hline & $\triangle P I M P A C T$ & $\triangle T O V$ & $\Delta E S$ & $\triangle M E S$ & $\triangle Q B A$ & $\triangle P Q B A$ \\
\hline Concurrent & -0.047 & 1.447 & 0.055 & 0.190 & 0.372 & 0.910 \\
\hline$t$-stats & -0.69 & 2.98 & 2.76 & 8.24 & 4.36 & 3.55 \\
\hline$P$-value & 0.493 & 0.003 & 0.006 & 0.000 & 0.000 & 0.001 \\
\hline$\%$ Pos & 53.54 & 75.88 & 65.23 & 81.25 & 66.94 & 68.95 \\
\hline$\%$ Pos\&Sig & 2.76 & 29.18 & 14.84 & 28.13 & 10.08 & 16.53 \\
\hline Lag & -0.112 & -0.014 & 0.001 & 0.008 & 0.089 & 0.075 \\
\hline$t$-stats & -1.72 & -0.03 & -0.05 & 0.31 & 1.37 & 0.60 \\
\hline$P$-value & 0.086 & 0.977 & 0.959 & 0.754 & 0.172 & 0.552 \\
\hline$\%$ Pos & 32.28 & 52.53 & 45.31 & 46.88 & 53.63 & 57.66 \\
\hline$\%$ Pos\&Sig & 5.51 & 4.28 & 3.91 & 8.98 & 4.84 & 8.47 \\
\hline Lead & -0.132 & 0.004 & -0.014 & 0.024 & -0.183 & -0.119 \\
\hline$t$-stats & -2.13 & 0.01 & -0.77 & 1.25 & -1.54 & -1.08 \\
\hline$P$-value & 0.034 & 0.991 & 0.441 & 0.213 & 0.124 & 0.282 \\
\hline$\%$ Pos & 28.74 & 51.75 & 42.97 & 52.34 & 43.15 & 41.13 \\
\hline$\%$ Pos\&Sig & 2.76 & 4.67 & 7.42 & 6.64 & 3.63 & 2.02 \\
\hline \multicolumn{7}{|l|}{ Sum } \\
\hline Mean & -0.291 & 1.436 & 0.040 & 0.222 & 0.278 & 0.867 \\
\hline$t$-stats & -1.86 & 1.92 & 1.16 & 5.16 & 1.52 & 2.27 \\
\hline$P$-value & 0.064 & 0.055 & 0.247 & 0.000 & 0.131 & 0.024 \\
\hline Median & -0.001 & 1.089 & 0.022 & 0.143 & 0.147 & 0.261 \\
\hline$P$-value & 0.950 & 0.000 & 0.021 & 0.000 & 0.003 & 0.000 \\
\hline Adj- $R^{2}$ Mean & 0.057 & 0.006 & 0.008 & 0.007 & 0.019 & 0.025 \\
\hline Median & 0.032 & 0.003 & 0.000 & 0.005 & 0.011 & 0.012 \\
\hline
\end{tabular}

This table reports the results of equation (7) that tests the market commonality in liquidity. For each stock, daily percentage changes in an individual stock's liquidity are regressed in time-series on the percentage changes in market liquidity. Market liquidity is calculated as an equally weighted cross-sectional average of the liquidity variables for all stocks included in the sample for a particular trading day. In each individual regression, the dependent variable stock is excluded from the market averages. PIMPACT, TOV, ES, MES, QBA and PQBA are liquidity measures that are defined in table 1 . The letter ' $\triangle$ ', preceding the acronym of liquidity measure e.g. $\triangle P I M P A C T$, refers to the percentage change in the liquidity variable across successive trading days, that is, for liquidity measure $L i q, \Delta L i q_{t}=\left(\operatorname{Liq}_{t}-\operatorname{Liq}_{t-1}\right) / L i q_{t-1}$ for trading day ${ }_{t}$. Cross-sectional averages of time-series slope coefficients are reported with the corresponding $t$-statistics. 'Concurrent', 'Lag', 'Lead' refer to the same, previous, and next trading day observations of market liquidity, respectively. '\% Pos' reports the proportion of positive coefficient whereas '\%Pos\&Sig' reports the percentage of the coefficients with $t$-statistics greater than +1.645 at $5 \%$ critical level using one-tailed test. 'Sum' refers to the summation of concurrent, lag and lead coefficients, with the corresponding $t$-statistics and ' $p$-value' of the sign test of the null hypothesis: Sum median $=0$. The coefficients of the additional regressors, concurrent, lag and lead values of market return and the percentage change in squared return (i.e. a proxy for individual firm changing volatility), are not reported. Adj- $R^{2}$ denotes the adjusted r-squared.

Moreover, in contrast to Chordia et al. (2000) but consistent with other studies, our coefficients estimate of lag and lead of market liquidity are insignificant except for the price impact measure. This implies a rapid adjustment in stocks' liquidity to the leading and lagged changes in market liquidity; there is no non-contemporaneous adjustment in liquidity that results from thin trading in the ASE.

In addition, focusing on the joint effect of concurrent, lag and lead market liquidity, the "Sum" of all market liquidity coefficients with the exception of the price impact measure are highly significant. The $p$-values of sign test are less than $1 \%$ and 5\% significant level. This implies that stocks' liquidity respond significantly across time to the changes in market-wide liquidity (see Pukthuanthong-Le \& Visaltanachoti, 2009). Finally, the average adjusted $R^{2}$ shows that the explanatory power of the individual regression is very low; it ranges from $0.6 \%$ to $5.7 \%$. Our low mean values of adjusted $R^{2}$ are consistent with those reported by Chordia et al. (2000), Brockman 
and Chung (2002) and others, but inconsistent with higher mean values of adjusted $R^{2}$ reported by Coughenour and Saad (2004). This suggests that there is a large noise component and/or other effects on daily changes in an individual stock's liquidity.

\subsection{Size Effect and Commonality in Liquidity}

Previous market microstructure literature shows that liquidity is affected by the size of the firm (see e.g. Benston \& Hagerman, 1974; Schultz, 1983; Stoll \& Whaley, 1983; Menyah \& Paudyal, 1996 among others). Therefore, the firm's size could have an impact on the degree of responsiveness of the changes in stock liquidity to the changes in market-wide liquidity. To examine the presence of the size effect on the degree of commonality in liquidity, the estimated coefficients of equation (7) are ranked based on the market capitalization of the firm at the beginning of the sample period and then sorted into three groups: small, medium and large.

Table 3. Market-wide commonality in liquidity by size

\begin{tabular}{|c|c|c|c|c|c|c|c|c|c|c|c|c|c|c|}
\hline & & \multirow{2}{*}{$\begin{array}{l}\text { No. of } \\
\text { firms }\end{array}$} & \multicolumn{2}{|c|}{ Concurrent } & \multicolumn{2}{|l|}{ Lag } & \multicolumn{2}{|l|}{ Lead } & \multicolumn{3}{|l|}{ Sum } & \multirow[b]{2}{*}{$P$-value } & \multicolumn{2}{|l|}{ Adj- $R^{2}$} \\
\hline & & & Mean & $t$-stats & Mean & $t$-stats & Mean & $t$-stats & Mean & $t$-stats & Median & & Mean & Median \\
\hline & Small & 82 & 0.008 & 0.07 & -0.168 & -1.23 & -0.118 & -1.09 & -0.278 & -1.04 & -0.003 & 0.741 & 0.056 & 0.040 \\
\hline \multirow[t]{3}{*}{$\triangle P I M P A C T$} & Medium & 83 & -0.177 & -1.48 & -0.134 & -1.23 & -0.055 & -0.76 & -0.366 & -1.36 & -0.020 & 0.188 & 0.047 & 0.027 \\
\hline & Large & 82 & 0.053 & 0.40 & 0.015 & 0.16 & -0.201 & -1.49 & -0.133 & -0.47 & 0.042 & 0.060 & 0.058 & 0.031 \\
\hline & Small & 82 & 0.837 & $3.11 * * *$ & 0.285 & 0.86 & 0.042 & 0.09 & 1.164 & $2.26 * *$ & 0.842 & 0.035 & 0.005 & 0.001 \\
\hline \multirow[t]{3}{*}{$\triangle T O V$} & Medium & 83 & 1.471 & $1.91^{*}$ & -0.285 & -0.60 & -0.368 & -0.47 & 0.818 & 0.47 & 1.378 & 0.002 & 0.006 & 0.003 \\
\hline & Large & 82 & 0.966 & $3.34 * * *$ & 1.045 & 1.09 & 0.415 & 0.74 & 2.426 & $1.67 *$ & 1.047 & 0.000 & 0.006 & 0.002 \\
\hline & Small & 82 & 0.081 & $2.63 * * *$ & 0.022 & 0.65 & 0.023 & 0.78 & 0.126 & $2.48 * *$ & 0.054 & 0.001 & 0.005 & 0.000 \\
\hline \multirow[t]{3}{*}{$\Delta E S$} & Medium & 83 & -0.008 & -0.23 & -0.012 & -0.51 & -0.044 & $-1.92 *$ & -0.064 & -1.26 & -0.023 & 0.510 & 0.004 & -0.001 \\
\hline & Large & 82 & 0.078 & $2.72 * * *$ & -0.031 & -1.03 & -0.009 & -0.24 & 0.037 & 0.72 & 0.022 & 0.097 & 0.010 & 0.001 \\
\hline & Small & 82 & 0.162 & $5.33^{* * * *}$ & -0.043 & -1.02 & 0.013 & 0.47 & 0.131 & $1.96^{*}$ & 0.143 & 0.003 & 0.007 & 0.007 \\
\hline \multirow[t]{3}{*}{$\triangle M E S$} & Medium & 83 & 0.170 & $5.59 * * *$ & 0.074 & $2.32 * *$ & -0.037 & -1.42 & 0.207 & $3.77 * * *$ & 0.143 & 0.008 & 0.003 & 0.001 \\
\hline & Large & 82 & 0.293 & $6.35^{* * *} *$ & -0.032 & -0.63 & 0.079 & $1.86^{*}$ & 0.340 & $3.51 * * *$ & 0.175 & 0.000 & 0.015 & 0.007 \\
\hline & Small & 82 & 0.377 & $1.81 *$ & 0.205 & 1.46 & -0.160 & -0.74 & 0.422 & 1.06 & 0.411 & 0.020 & 0.023 & 0.014 \\
\hline \multirow[t]{3}{*}{$\triangle Q B A$} & Medium & 83 & 0.519 & $4.22 * * *$ & 0.093 & 1.08 & -0.425 & -1.59 & 0.187 & 0.60 & 0.104 & 0.188 & 0.023 & 0.016 \\
\hline & Large & 82 & 0.245 & $2.86^{* * * *}$ & 0.012 & 0.12 & 0.019 & 0.19 & 0.276 & 1.23 & 0.049 & 0.151 & 0.010 & 0.007 \\
\hline & Small & 82 & 1.213 & $1.86^{*}$ & 0.106 & 0.39 & -0.220 & -1.17 & 1.100 & 1.23 & 0.723 & 0.001 & 0.033 & 0.020 \\
\hline \multirow[t]{2}{*}{$\triangle P Q B A$} & Medium & 83 & 0.799 & $2.69 * * *$ & 0.184 & 1.03 & -0.364 & $-1.79 *$ & 0.620 & 1.19 & 0.308 & 0.028 & 0.022 & 0.012 \\
\hline & Large & 82 & 0.821 & $2.93 * * *$ & -0.026 & -0.13 & 0.161 & 0.97 & 0.956 & $1.87 *$ & 0.046 & 0.224 & 0.021 & 0.007 \\
\hline
\end{tabular}

Note. This table reports the results of equation (7) that tests the market commonality in liquidity when the sample is partitioned into three groups according to the market capitalization of the firms at the beginning of sample period. For each stock, daily percentage changes in an individual stock's liquidity are regressed in time-series on the percentage changes in market liquidity. Market liquidity is calculated as an equally weighted cross-sectional average of the liquidity variables for all stocks included in the sample for a particular trading day. In each individual regression, the dependent variable stock is excluded from the market averages. PIMPACT, TOV, ES, MES, QBA and PQBA are liquidity measures that are defined in table 1 . The letter ' $\triangle$ ', preceding the acronym of liquidity measure e.g. $\triangle P I M P A C T$, refers to the percentage change in the liquidity variable across successive trading days, that is, for liquidity measure $\operatorname{Liq}, \Delta \operatorname{Liq}_{t}=\left(\operatorname{Liq}_{t}-\operatorname{Liq}_{t-1}\right) / \operatorname{Liq}_{t-1}$, for trading day ${ }_{t}$. Cross-sectional averages of time-series slope coefficients are reported with the corresponding $t$-statistics. 'Concurrent', 'Lag', 'Lead' refer to the same, previous, and next trading day observations of market liquidity, respectively. Adj- $\mathrm{R}^{2}$ denotes the adjusted r-squared. $* * *, * *$ and $*$ indicate significance at $1 \%, 5 \%$ and $10 \%$, respectively.

Table 3 reports the results of the size effect on commonality. The results provide ample evidence of the existence of size effect in the commonality in liquidity. Apart from the price impact measure, the average coefficient of concurrent market liquidity is statistically significant in all three size groups and shows different patterns with firm size. More specifically, the turnover ratio results show that the medium size group has the highest sensitivity to market-wide changes, which implies that investors who trade medium size firms react to the changes in market-wide liquidity by revising the number of shares they are willing to trade. The medium size group of quoted bid-ask shows the highest sensitivity to the changes in market-wide liquidity, which is consistent with those reported in Brockman and Chung (2002). However, with exception of modified effective spread, the small size group of effective spread (i.e. Roll measure), quoted bid-ask spread and proportional bid-ask spread show greater response to market-wide bid-ask spread compared to the large size group (Note 6). This is inconsistent with Chordia et al. (2000) and Fabre and Frino (2004) who find that the bid-ask spreads of large firms show 
greater sensitivity to market-wide changes. This implies that traders in the ASE tend to adjust bid and ask prices more for small stocks than for large stocks, which is likely to be induced by a high level of information asymmetry that is related to small firms. Alternatively, the strongest response of a small firm's liquidity to market-wide movements, in the case of quoted and effective spread measures, could be justified by the size of minimum tick size. In the ASE, both small and large firms have the same minimum tick size: 1 qirsh (i.e piaster). As a result, small firms show the highest sensitivity to market-wide movement compared with large firms. In sum, the empirical results support the existence of commonality in liquidity across all size groups.

\subsection{Market-Wide and Industry-Wide Commonality in Liquidity}

Chordia et al. (2000) argue that some types of information, such as developing new technology, result in an information asymmetry within a particular industry, which could affect the degree of responsiveness of firms' liquidity to the changes in industry-wide liquidity in different directions. Consequently, we examine the existence of industry-wide commonality in liquidity using the following regression model:

$$
\begin{gathered}
\Delta L i q_{i, t}=\alpha_{i}+\beta_{i 1} \Delta L i q_{M, t}+\beta_{i 2} \Delta L i q_{M, t+1}+\beta_{i 3} \Delta L i q_{M, t-1}+\delta_{i 1} \Delta L i q_{I, t} \\
+\delta_{i 2} \Delta L i q_{I, t+1}+\delta_{i 3} \Delta L i q_{I, t-1}+\gamma_{i 1} \operatorname{Ret}_{M, t}+\gamma_{i 2} \operatorname{Ret}_{M, t+1}+\gamma_{i 3} \operatorname{Ret}_{M, t-1}+\gamma_{i} \sigma_{i, t}+\varepsilon_{i, t}
\end{gathered}
$$

Where $\Delta L i q_{I, t}$ is the concurrent percentage change in industry-wide liquidity, which is calculated as equally weighted cross-sectional average of liquidity for all stocks traded in day $t$. As with market-wide liquidity, stock $i$ is excluded from the industry average. $\Delta L i q_{I, t+1}$ and $\Delta L i q_{I, t-1}$ are one period lead and lag of the industry average liquidity variable. All other variables are the same as defined in model (7). The stocks in the sample are classified into one of six industries including banks, financial services, industrials, insurance, real estate, services based on the ASE classification.

Table 4 reports the regression results of equation (8). Consistent with the results of Fabre and Frino (2004) and Galariotis and Giouvris (2007), our results provide evidence on the absence of industry commonality in liquidity. The coefficient of the concurrent change in industry-wide liquidity is statistically insignificant: the values of $t$-statistics range from -0.74 to 1.58 . However, changes in concurrent market-wide liquidity continue to exert an impact on an individual firm's liquidity. This implies that, in the ASE, industry-wide liquidity does not have any role in explaining the changes in an individual firm's liquidity. According to Galariotis and Giouvris (2007), the firm specific noise variation could be the reason for the insignificant impact of industry-wide commonality.

The independence of estimation error across equations reflects the reliability of $t$-statistics results that are reported in this paper. Following Chordia et al. (2000) and others, the reliability of $t$-statistics results is checked by investigating the residuals from market and industry regression (i.e. equation (8) by performing time-series regressions between adjacent residuals as follows:

$$
\varepsilon_{i+1, t}=\alpha_{i, 0}+\alpha_{i, 1} \varepsilon_{i, t}+\xi_{i, t}
$$

Where $\alpha_{\mathrm{i}, 0}$ and $\alpha_{\mathrm{i}, 1}$ are the estimated coefficients and $\xi_{\mathrm{i}, \mathrm{t}}$ is an estimated disturbance. The $t$-statistics of the estimated coefficient of error term for stock $i$ provide evidence about the cross-sectional dependence; if the cross-sectional average of $t$-statistic is statistically significant, this means that residuals are not independent and thus the results are invalid. The estimation results of equation (9) are reported in table 5. The results show that there is little evidence of dependency. The cross-sectional $t$-statistics range from 0.069 to 0.289 . Furthermore, consistent with other studies, the average correlation is very low and in some cases close to zero, which implies that adjusting for cross-equation dependence would not change the results.

\section{Conclusion}

Previous research of market microstructure has extensively focused on examining the firm-specific attributes of liquidity. Following the new trend in market microstructure literature, this study has examined the presence of commonality in liquidity using a sample of stocks listed on ASE. Based on the methodology of Chordia et al. (2000), the results provide ample evidence on the market-wide commonality for Jordanian stocks. More specifically, the change in an individual stock's liquidity is significantly affected by the change in market-wide liquidity, which is consistent with the evidence reported by previous studies for quote-driven and order-driven markets. However, the commonality in the ASE is more pervasive than that reported for the Hong Kong Stock Exchange (Brockman \& Chung, 2002) and for the Australian Stock Exchange (Fabre \& Frino, 2004). The results also provide evidence on the presence of the size effect in the amount of commonality in liquidity. The commonality in effective spread (i.e. Roll measure), quoted spread and proportional quotes spread is more pronounced for small stocks, although it is even more pronounced for middle-size stocks in the case of turnover ratio. Consistent with Fabre and Frino (2004) and Galariotis and Giouvris (2007) but in contrast to Chordia et al. 
(2000), Brockman and Chung (2002) and Pukthuanthong-Le and Visaltanachoti (2009), the results provide no evidence on the presence of industry-wide commonality in liquidity.

Table 4. Market-wide and Industry-wide commonality in liquidity

\begin{tabular}{|c|c|c|c|c|c|c|c|c|c|c|c|c|c|c|c|c|c|c|}
\hline & & \multicolumn{4}{|c|}{ Concurrent } & \multicolumn{3}{|l|}{$\mathrm{Lag}$} & \multicolumn{4}{|c|}{ Lead } & \multicolumn{3}{|c|}{ Sum } & \multicolumn{3}{|c|}{ Adj-R2 } \\
\hline & & Mean & t-stats & $\%$ Pos & $\begin{array}{l}\% \text { Pos } \\
\& \text { Sig }\end{array}$ & Mean & $\mathrm{t}$-stats & $\%$ Pos & $\begin{array}{l}\% \text { Pos } \\
\& \text { Sig }\end{array}$ & Mean & t-stats & $\%$ Pos & $\begin{array}{l}\% \text { Pos } \\
\& \text { Sig }\end{array}$ & Mean & t-stats & Median & Mean & Median \\
\hline \multirow{2}{*}{$\triangle$ АPIMPACT } & MKT & -0.064 & -0.74 & 50.59 & 3.56 & -0.097 & -1.44 & 43.87 & 1.98 & -0.121 & $-1.79^{*}$ & 47.43 & 5.14 & -0.282 & -1.61 & -0.019 & \multirow{2}{*}{0.060} & \multirow{2}{*}{0.031} \\
\hline & IND & 0.029 & 1.30 & 46.25 & 3.95 & -0.013 & -1.35 & 39.13 & 1.58 & -0.005 & -0.36 & 35.97 & 2.77 & 0.010 & 0.38 & $-0.003^{* * *}$ & & \\
\hline$\triangle T O V$ & MKT & 1.326 & $2.54 * *$ & 70.43 & 22.57 & 0.077 & 0.13 & 51.36 & 3.89 & 0.446 & 1.20 & 52.14 & 2.33 & 1.849 & $2.23^{* *}$ & $0.774^{* * * *}$ & 0.003 & 0.003 \\
\hline \multirow{2}{*}{$\Delta E S$} & MKT & 0.055 & $2.15^{* * *}$ & 60.55 & 11.72 & -0.018 & -0.75 & 44.14 & 5.08 & -0.022 & -1.21 & 46.48 & 4.69 & 0.015 & 0.37 & 0.019 & \multirow{2}{*}{0.006} & \multirow{2}{*}{0.001} \\
\hline & IND & 0.012 & 0.75 & 55.86 & 8.59 & 0.021 & 1.30 & 51.56 & 5.86 & -0.025 & $-1.74 *$ & 46.48 & 5.08 & 0.008 & 0.28 & 0.007 & & \\
\hline \multirow{2}{*}{$\triangle M E S$} & MKT & 0.211 & $6.61^{* * * *}$ & 82.42 & 24.22 & 0.037 & 1.12 & 50.78 & 7.03 & 0.016 & 0.67 & 53.91 & 6.64 & 0.264 & $4.65^{\text {**** }}$ & $0.133^{* * * *}$ & \multirow{2}{*}{0.008} & \multirow{2}{*}{0.008} \\
\hline & IND & 0.035 & 1.58 & 57.03 & 14.84 & -0.010 & -0.79 & 47.27 & 5.08 & -0.009 & -0.54 & 44.14 & 3.52 & 0.016 & 0.52 & 0.008 & & \\
\hline \multirow{2}{*}{$\triangle Q B A$} & MKT & 0.399 & $4.53^{* * * *}$ & 67.74 & 9.27 & 0.042 & 0.43 & 53.23 & 4.84 & -0.209 & -1.51 & 47.58 & 3.23 & 0.232 & 1.09 & $0.148^{* * * *}$ & \multirow{2}{*}{0.025} & \multirow{2}{*}{0.012} \\
\hline & IND & -0.025 & -0.74 & 44.35 & 2.42 & 0.011 & 0.27 & 48.39 & 3.23 & 0.003 & 0.09 & 37.50 & 3.63 & -0.011 & -0.17 & $-0.016^{*}$ & & \\
\hline$\triangle P Q B A$ & IND & -0.029 & -0.46 & 42.11 & 2.83 & -0.024 & -0.58 & 42.11 & 2.83 & -0.008 & -0.16 & 38.46 & 3.24 & -0.061 & -0.58 & -0.008 & 0.021 & 0.013 \\
\hline
\end{tabular}

Note. This table reports the results of equation (8) that tests the market and industry commonality in liquidity. For each stock, daily percentage changes in an individual stock's liquidity are regressed in time-series on the percentage changes in market liquidity and the percentage changes in industry liquidity. Market liquidity (Industry liquidity) is calculated as an equally weighted cross-sectional average of the liquidity variables for all stocks included in the sample (all stocks included in the same industry) for a particular trading day. In each individual regression, the dependent variable stock is excluded from both the market averages and industry averages. PIMPACT, TOV, ES, MES, QBA and PQBA are liquidity measures that are defined in table 1 . The letter ' $\triangle$ ', preceding the acronym of liquidity measure e.g. $\triangle P I M P A C T$, refers to the percentage change in the liquidity variable across successive trading days, that is, for liquidity measure $\operatorname{Liq}_{\text {, }} \Delta \operatorname{Liq}_{t}=\left(\operatorname{Liq}_{t}-\operatorname{Liq}_{t-1}\right) / \operatorname{Liq}_{t-1}$ for trading day ${ }_{t}$. Cross-sectional averages of time-series slope coefficients are reported with the corresponding $t$-statistics. 'Concurrent', 'Lag', 'Lead' refer to the same, previous, and next trading day observations of market liquidity, respectively. '\% Pos' reports the proportion of positive coefficient where as '\% Pos\&Sig' reports the percentage of the coefficients with $t$-statistics greater than +1.645 at $5 \%$ critical level using one-tailed test. 'Sum' refers to the summation of concurrent, lag and lead coefficients, with the corresponding $t$-statistics and ' $p$-value' of the sign test of the null hypothesis: Sum median $=0$ is not reported for the sake of brevity and replaced, instead, with stars to indicate significance. The coefficients of the additional repressors, concurrent, lag and lead values of market return and the percentage change in squared return (i.e. a proxy for individual firm changing volatility), are not reported. Adj- $\mathrm{R}^{2}$ denotes the adjusted $\mathrm{r}$-squared. $* * *, * *$ and $*$ indicate significance at $1 \%, 5 \%$ and $10 \%$, respectively.

Table 5. Check for cross-equation dependence in estimation error

\begin{tabular}{|c|c|c|c|c|c|}
\hline & Average Correlation & Mean t & Median $\mathrm{t}$ & $|t|>1.645(\%)$ & $|\mathrm{t}|>1.96(\%)$ \\
\hline$\triangle P I M P A C T$ & 0.135 & 0.178 & -0.086 & 10.98 & 7.72 \\
\hline$\triangle T O V$ & 0.009 & 0.122 & -0.073 & 9.52 & 5.95 \\
\hline$\triangle E S$ & 0.012 & 0.069 & 0.101 & 11.65 & 6.43 \\
\hline$\triangle M E S$ & -0.012 & 0.067 & 0.038 & 16.00 & 10.00 \\
\hline$\triangle Q B A$ & -0.191 & 0.273 & -0.149 & 12.92 & 10.00 \\
\hline$\triangle P Q B A$ & -0.102 & 0.289 & -0.128 & 15.83 & 11.67 \\
\hline
\end{tabular}

Note. This table shows the results of pair-wise regression equation (9); the residuals for stock $i+1$, that results from the time-series regression of individual liquidity measures on equally weighted market and industry liquidity (equation (8), are regressed on the residuals for stock $i$. More specifically, it reports the average correlation coefficient, the sample mean and median $t$-statistic of the regression slope coefficient and the frequency of absolute $t$-statistics for the slope which are exceeding typical critical levels $10 \%$ and $5 \%$ in two tails test. PIMPACT, TOV, ES, MES, $Q B A$ and $P Q B A$ are liquidity measures that are defined in table 1 . The letter ' $\triangle$ ', preceding the acronym of liquidity measure e.g. $\triangle P I M P A C T$, refers to the percentage change in the liquidity variable across successive trading days, that is, for liquidity measure $\left.\operatorname{Liq}, \Delta L i q_{t}=\left(\operatorname{Liq}_{t}-\operatorname{Liq}_{t-1}\right)\right)$ Liq $_{t-1}$ for trading day t.

\section{References}

Acharya, V., \& Pedersen, L. (2005). Asset pricing with liquidity risk. Journal of Financial Economics, 77, 375-410. http://dx.doi.org/10.1016/j.jfineco.2004.06.007 
Aitken, M., \& Comerton-Forde, C. (2003). How should liquidity be measured? Pacific-Basin Finance Journal, 11, 45-59. http://dx.doi.org/10.1016/S0927-538X(02)00093-8

Amihud, Y. (2002). Illiquidity and stock returns:cross-section and time-series effect. Journal of Financial Markets, 5, 31-56. http://dx.doi.org/10.1016/S1386-4181(01)00024-6

Benston, G. J., \& Hagerman, R. L. (1974). Determinants of bid-asked spreads in the over-the-counter market. Journal of Financial Economics, 1, 353-364. http://dx.doi.org/10.1016/0304-405X(74)90014-2

Brockman, P., \& Chung, D. Y. (2002). Commonality in liquidity: evidence from an order-driven market structure. The Journal of Financial Research, 25, 521-539. http://dx.doi.org/10.1111/1475-6803.00035

Chordia, T., Roll, R., \& Subrahmanyam, A. (2000). Commonality in liquidity. Journal of Financial Economics, 56, 3-28. http://dx.doi.org/10.1016/S0304-405X(99)00057-4

Comerton-Forde, C., \& Rydge, J. (2006). The current state of Asia-Pacific stock exchanges: A critical review of market design. Pacific-Basin Finance Journal, 14, 1-32. http://dx.doi.org/10.1016/j.pacfin.2005.05.002

Coughenour, J. F., \& Saad, M. M. (2004). Common market makers and commonality in liquidity. Journal of Financial Economics, 73, 37-69. http://dx.doi.org/10.1016/j.jfineco.2003.05.006

Datar, V. T., Naik, N. Y., \& Radcliffe, R. (1998). Liquidity and stock returns: An alternative test. Journal of Financial Markets, 1, 203-219. http://dx.doi.org/10.1016/S1386-4181(97)00004-9

Demsetz, H. (1968). The cost of transacting. Quarterly Journal of Economics, 82, 33-53. http://dx.doi.org/10.2307/1882244

Fabre, J., \& Frino, A. (2004). Commonality in liquidity: Evidence from the Australian Stock Exchange. Accounting and Finance, 44, 357-368. http://dx.doi.org/ 10.1111/j.1467-629x.2004.00117.x

Galariotis, E. C., \& Giouvris, E. (2007). Liquidity Commonality in the London Stock Exchange. Journal of Business Finance \& Accounting, 34, 374-388. http://dx.doi.org/ 10.1111/j.1468-5957.2006.00664.x

Goyenko, R. Y., Holden, C. W., \& Trzcinka, C. A. (2009). Do liquidity measures measure liquidity? Journal of Financial Economics, 92, 153-181. http://dx.doi.org/10.1016/j.jfineco.2008.06.002

Handa, P., Schwartz, R. A., \& Tiwari, A. (1998). The Ecology of An Order-Driven Market System. Journal of Portfolio Management, 24, 47-55. http://dx.doi.org/ 10.3905/jpm.24.2.47

Hasbrouck, J., \& Seppi, D. J. (2001). Common factors in prices, order flows, and liquidity. Journal of Financial Economics, 59, 383-411. http://dx.doi.org/ 10.1016/S0304-405X(00)00091-X

Huberman, G., \& Halka, D. (2001). Systematic liquidity. The Journal of Financial Research, 24, 161-178. http://dx.doi.org/ 10.1111/j.1475-6803.2001.tb00763.x

Lagoarde-Segot, T., \& Lucey, B. M. (2008). Efficiency in emerging markets-Evidence from the MENA region. Journal of International Financial Markets, Institutions and Money, 18, 94-105. http://dx.doi.org/10.1016/j.intfin.2006.06.003

Martínez, M. A., Nieto, B., Rubio, G., \& Tapia, M. (2005). Asset pricing and systematic liquidity risk: An empirical investigation of the Spanish Stock Market. International Review of Economics \& Finance, 14, 81-103. http://dx.doi.org/10.1016/j.iref.2003.12.001

Menyah, K., \& Paudyal, K. (1996). The determinants and dynamics of bid-ask spreads on the london stock $\begin{array}{lllll}\text { exchange. Journal of } & \text { Financial }\end{array}$ http://dx.doi.org/10.1111/j.1475-6803.1996.tb00220.x

Pastor, L., \& Stambaugh, R. F. (2003). Liquidity risk and expected stock returns. The Journal of Political Economy, 111, 642-685. http://dx.doi.org/ 10.1086/374184

Pukthuanthong-Le, K., \& Visaltanachoti, N. (2009). Commonality in liquidity: Evidence from the Stock Exchange of Thailand. Pacific-Basin Finance Journal, 17, 80-99. http://dx.doi.org/10.1016/j.pacfin.2007.12.004

Roll, R. (1984). A Simple Implicit Measure of the Effective Bid-Ask Spread in an Efficient Market. The Journal of Finance, 39, 1127-1139. http://dx.doi.org/10.2307/2327617

Schultz, P. (1983). Transaction costs and the small firm effect. a comment. Journal of Financial Economics, 12, 81-88. http://dx.doi.org/10.1016/0304-405X(83)90028-4

Stoll, H. R., \& Whaley, R. E. (1983). Transaction costs and the small firm effect. Journal of Financial, 
Economics 12, 57-79. http://dx.doi.org/10.1016/0304-405X(83)90027-2

Tayeh, M. I. D. (2010). A Comparative Analysis of the Determinants and Pricing of Liquidity in Floor and Electronic Trading Systems. Doctoral thesis, Durham University. Retrieved from http://etheses.dur.ac.uk/333/

\section{Notes}

Note 1. Source: World Bank World Development Indicators Database 2014.

Note 2. As a result of capital market reform in 1999 the Securities Depository Center (SDC) was established as an independent institution that offers custodian services of securities' ownership and performs settlement and clearance operations.

Note 3. Source: Amman Stock Exchange website, www.ase.com.jo.

Note 4. According to the listing requirements, companies listed on the first market must have days of trading that are not less than $20 \%$ of the overall trading days over the year. But, if the number of trading days is less than $20 \%$ the company will be listed on the second market (Amman Stock Exchange website, www.ase.com.jo).

Note 5. Illiquidity ratio and price impact are used interchangeably.

Note 6. Brockman and Chung (2002) argue that there is no difference between effective spread and quoted spread in an electronic order-driven market because trades are executed at posted bid and ask prices.

\section{Copyrights}

Copyright for this article is retained by the author(s), with first publication rights granted to the journal.

This is an open-access article distributed under the terms and conditions of the Creative Commons Attribution license (http://creativecommons.org/licenses/by/3.0/). 